Int. J. Electrochem. Sci., 14 (2019) $4546-4556$

\title{
Electrochemical Characterization of Anodic Oxide Film on TC11 Alloy in Sulfate Solution at High Temperature and High Pressure
}

Lei Zha ${ }^{1,2}$, Heping $\mathrm{Li}^{1, *}$, Ning Wang ${ }^{1}$

${ }^{1}$ Key Laboratory of High-temperature and High-pressure Study of the Earth's Interior, Institute of Geochemistry, Chinese Academy of Sciences, Guiyang 550081, P. R. China

${ }^{2}$ University of Chinese Academy of Sciences, Beijing 100049, P. R. China

*E-mail: liheping@vip.gyig.ac.cn

doi: $10.20964 / 2019.05 .35$

Received: 8 January 2019 / Accepted: 26 February 2019 / Published: 10 April 2019

The oxide films studied in this work were prepared by potentiostatic anodic oxidation of TC11 alloy in $0.01 \mathrm{M}$ sodium sulfate solutions at different anodizing potentials at $300^{\circ} \mathrm{C}$ and $10 \mathrm{MPa}$. This work aimed to study the effect of film formation potential on the passivity of the TC11 alloy in high temperature sodium sulfate. Electrochemical impedance spectroscopy (EIS) combined with Mott-Schottky (MS) measurements were used to investigate the electrochemical properties of the as-grown anodic passive films on theTC11 alloy. The experimental data were also interpreted using the point defect model (PDM). An equivalent circuit was proposed to fit the EIS experimental data, leading to the determination of oxide film resistance, with the increase of the film-forming potential film resistance increase. According to the MS analysis, the anodic oxidation passivation film on the TC11 alloy was an n-type semiconductor, and the main point defects were oxygen vacancies. The calculated donor density was found to decrease exponentially with an increase in the film-forming potential, while the passive film thickness increases linearly with the applied potential. These experimental conclusions were consistent with the theoretical predictions of the PDM.

Keywords: TC11 alloy; Anodic oxide film; EIS; Mott-Schottky; High temperature

\section{$\underline{\text { FULL TEXT }}$}

(C) 2019 The Authors. Published by ESG (www.electrochemsci.org). This article is an open access article distributed under the terms and conditions of the Creative Commons Attribution license (http://creativecommons.org/licenses/by/4.0/). 